City University of New York (CUNY)

CUNY Academic Works

2016

EXPERIENTIAL LEARNING OPPORTUNITIES THROUGH NASA

STEM CONTENT ALLOWS GREATER GRASS ROOT-LEVEL

UNDERSTANDING OF THE PRESENT DAY'S EXTREME CLIMATE

CHANGE SCENARIO

Nazrul I. Khandaker

CUNY York College

Stanley Schleifer

CUNY York College

Matthew Khargie

CUNY York College

How does access to this work benefit you? Let us know!

More information about this work at: https://academicworks.cuny.edu/yc_pubs/169

Discover additional works at: https://academicworks.cuny.edu

This work is made publicly available by the City University of New York (CUNY).

Contact: AcademicWorks@cuny.edu 


\section{EXPERIENTIAL LEARNING OPPORTUNITIES THROUGH NASA STEM CONTENT ALLOWS GREATER GRASS ROOT-LEVEL UNDERSTANDING OF THE PRESENT DAY'S EXTREME CLIMATE CHANGE SCENARIO \\ KHANDAKER, Nazrul I., Geology Discipline, Earth and Physical Sciences, York College of CUNY, 94-20 Guy R. Brewer Blvd, Jamaica, NY 11451 \\ SCHLEIFER Stanley Geology Discipline Eline, Earth and Physical Sciences, York College of C4NY, 94-20 Guy R. Brewer Blvd, Jamaica, NY 11451, Matthew, Physics, York College (CUNY), 94-20 Guy R. Brewer Blvd, Jamaica, NY 11451 and WILLS, Newrence, NASA MAA Project (York College), York \\ College (CUNY), 94-20 Guy R. Brewer Blvd, Jamaica, NY 11451, mattkhargie@gmail.com}

College THE CITY UNIVERSITY OF NEW YORK
The NASA MAA (MUREP Aerospace Academy) project at York College has demonstrated a track record of providing experiential earning opportunities (ELO) to its participating students. ELOs associated with MAA are designed to increase learners involvement, knowledge, comprehension and application of earning in one or more STEM subjects/disciplines. They involve inquiry-and-activity-based learning approaches designed for the level of the learner to inspire, engage, and educate while progressively challenging each student. ELO activities enable earners to acquire knowledge, understand what they have learned, and apply that knowledge through inquiry-based tasks. Specifically, we are prepared to address the following priority: Encourage, increase, and sustain youth and public engagement in STEM-Expand the number of U.S. youth (especially those from traditionally underrepresented groups) who have an effective, authentic STEM experience each year prior to completing high school. Being in southeast Queens, York's program is essentially playing a pivotal role to disseminate STEM resources to minority persons eagerly seeking content knowledge to further their education. Through MUREP, we are committed to advance understanding of the earth and develop technologies to improve the quality of life on our home planet. The introduction of a curriculum enhancement activity (CEA) to the K9-16 students is becoming a new initiative of our MAA project, as well as the formal addition of climate change curricula to the MAA 7-9th grades, and supplying the oversight and resources to accomplish that goal. Numerous studies have shown that providing climate change curriculum to the middle to high school students can allow greater grass root-level understanding of the changing phenomena and scientific constraints associated with such dramatic changes we are now facing. NASA's Science Directorate in conjunction with MAA will enable us to train MAA students and pre-service teachers in this endeavor and bring greater prominence of the MAA STEM contents to the participating students and disseminate real-time data for a realistic overview of the climate change scenario.

NASA MAA STEM Outreach Grant Funded This Project.

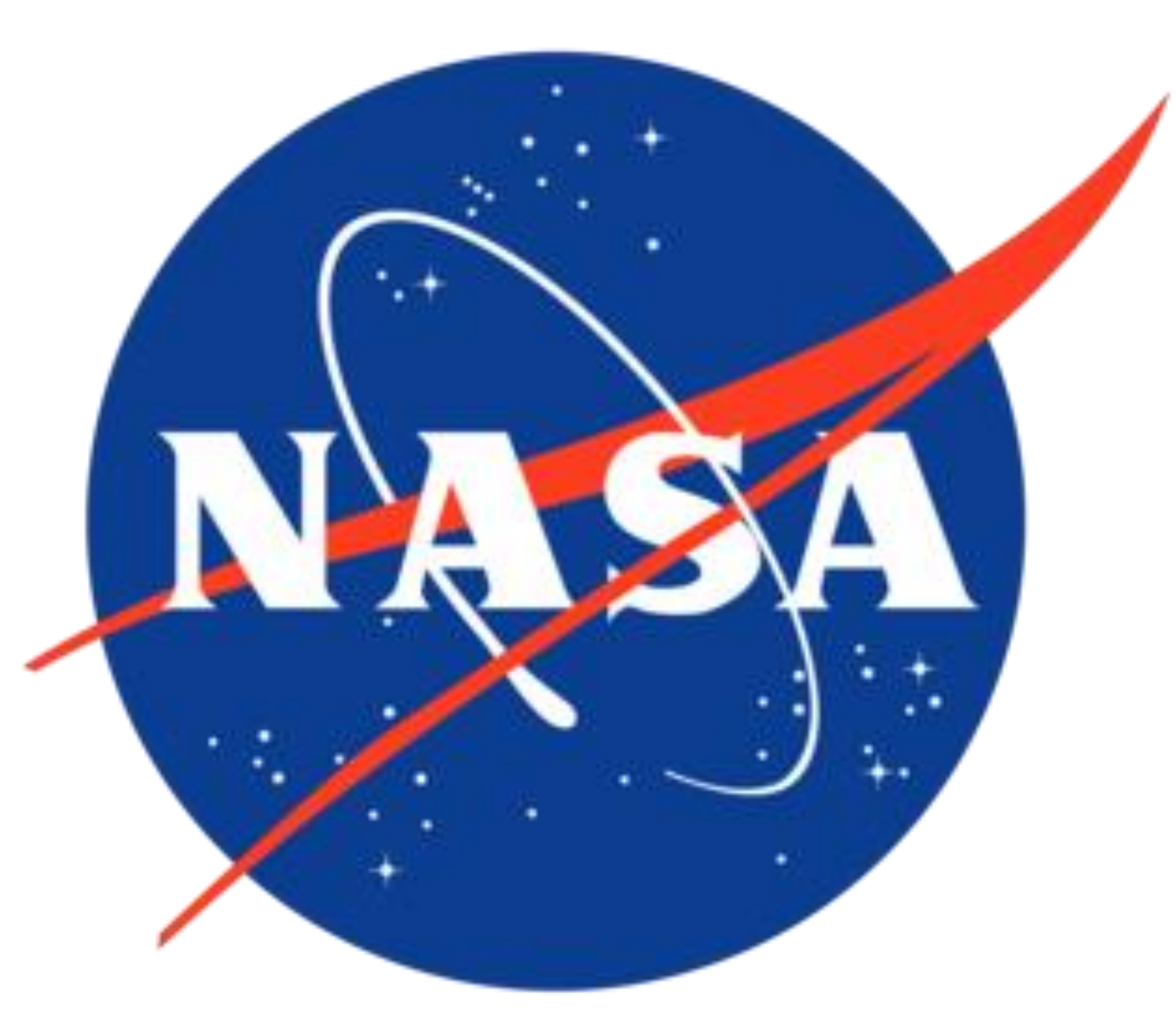

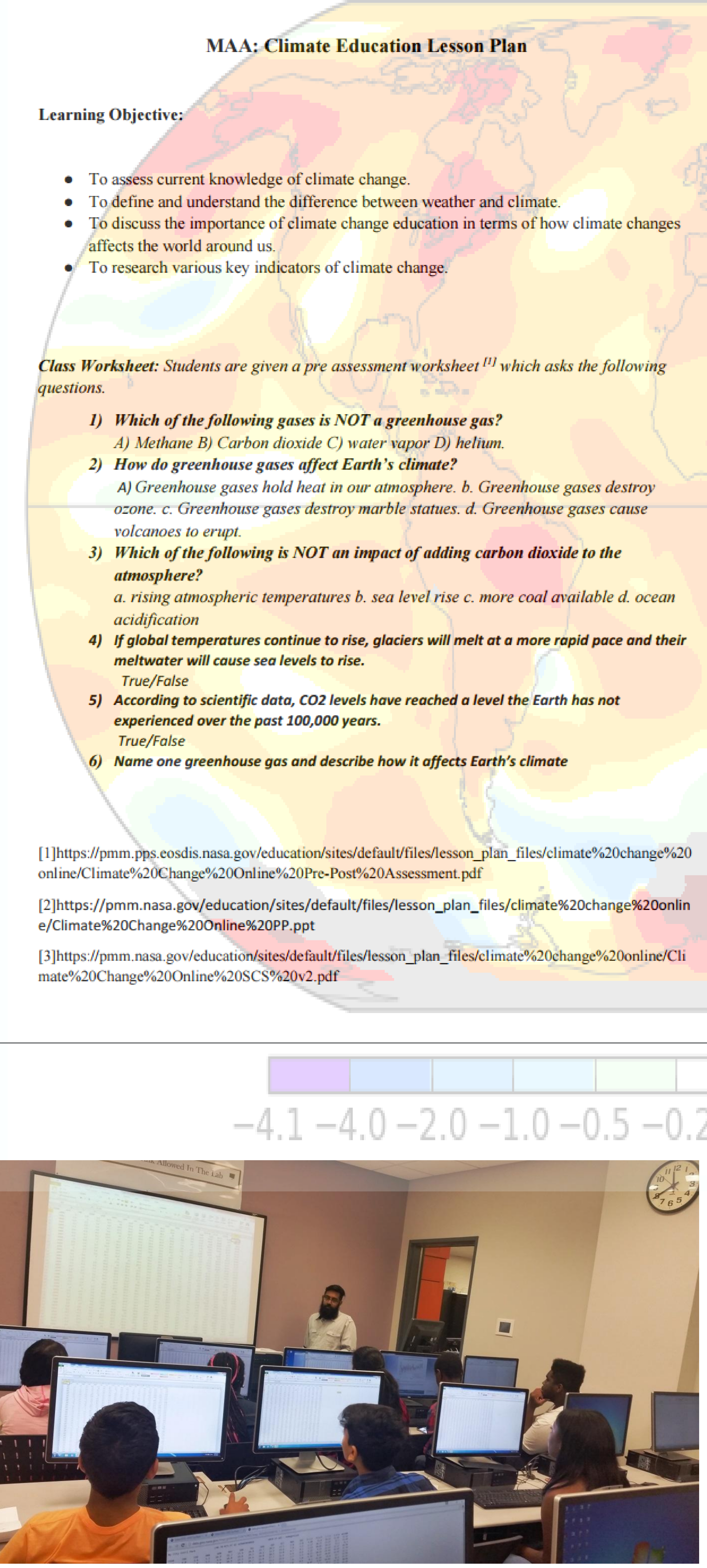

Students examining climate data from the New York Central Park Station. Instead of reading data off a graph the students will be analyzing the raw data and creating their own graphs.

Each group of students were able to pick a key indicator and given time to research that indicator using the resources provided by NASA run websites.
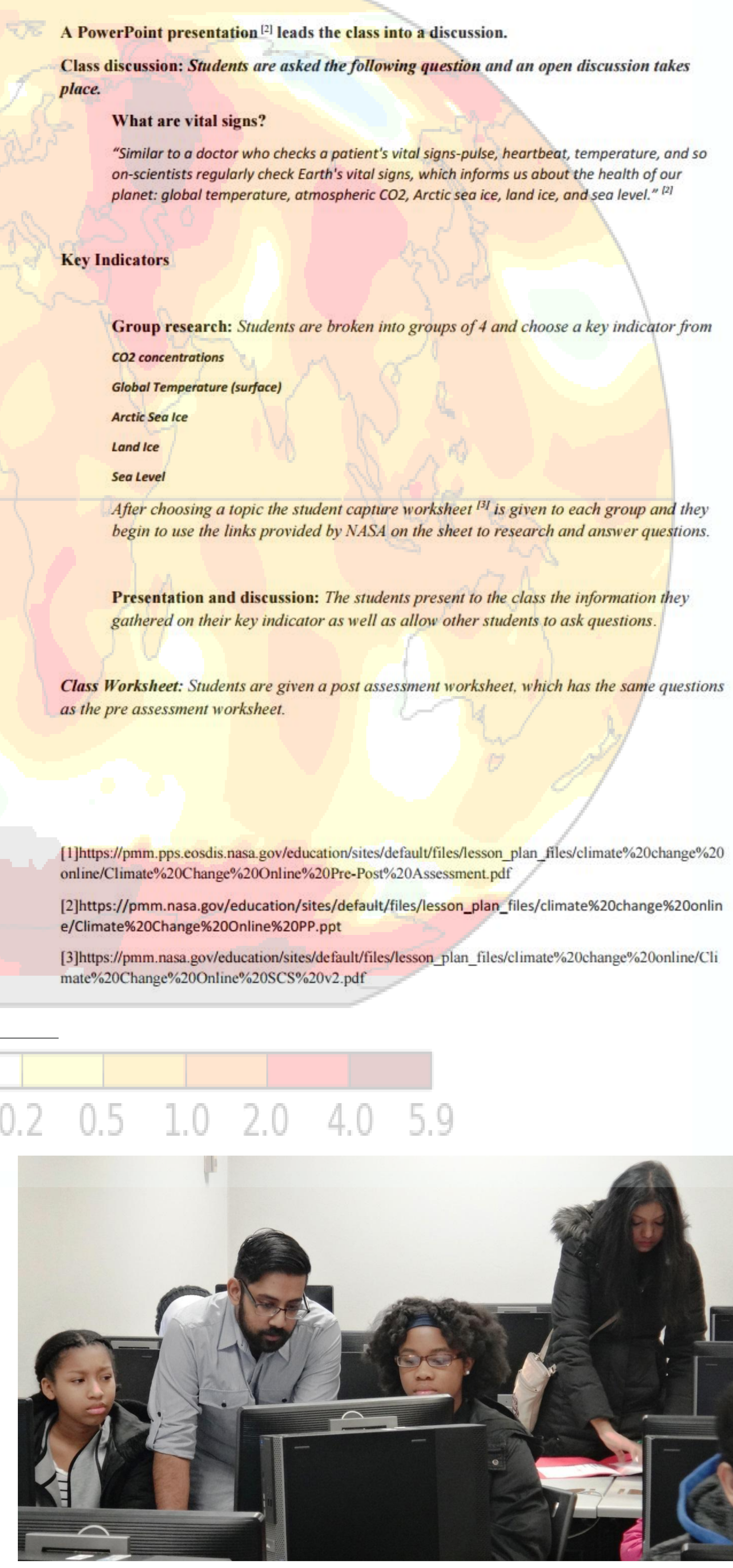

For many of the students this is their first time looking at climate data, which a majority of students only familiar with the term climate change not knowing the importance and/or the causes of climate change.

Before the lesson began every student was given a Pre-Assessment worksheet to gauge the knowledge of climate change that students new to the MAA program have.

After the lesson the students are then given a PostAssessment worksheet this aids the instructors in determining how effective the lesson was for the students.

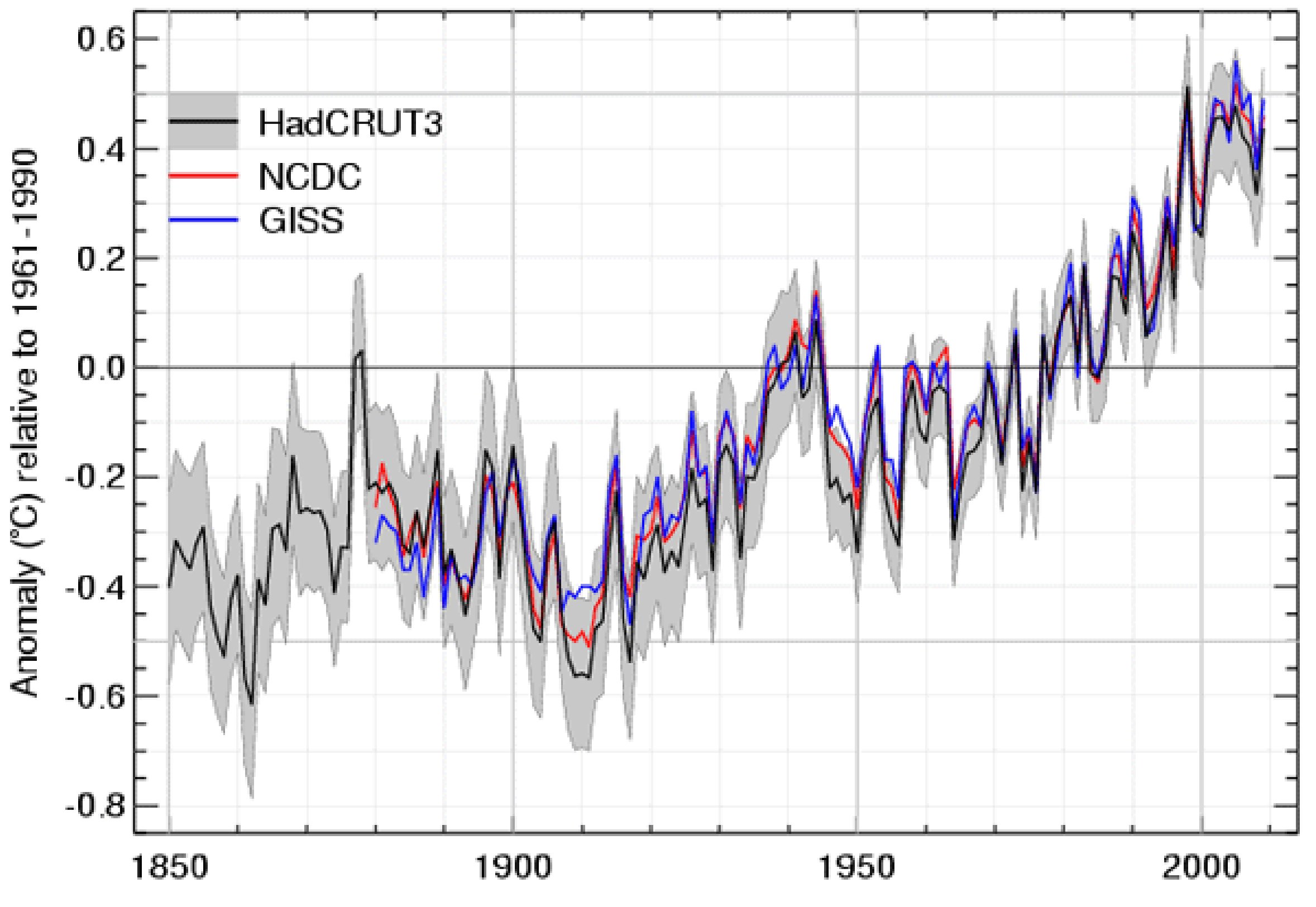

An example of the type of graphs the students made for their data analysis

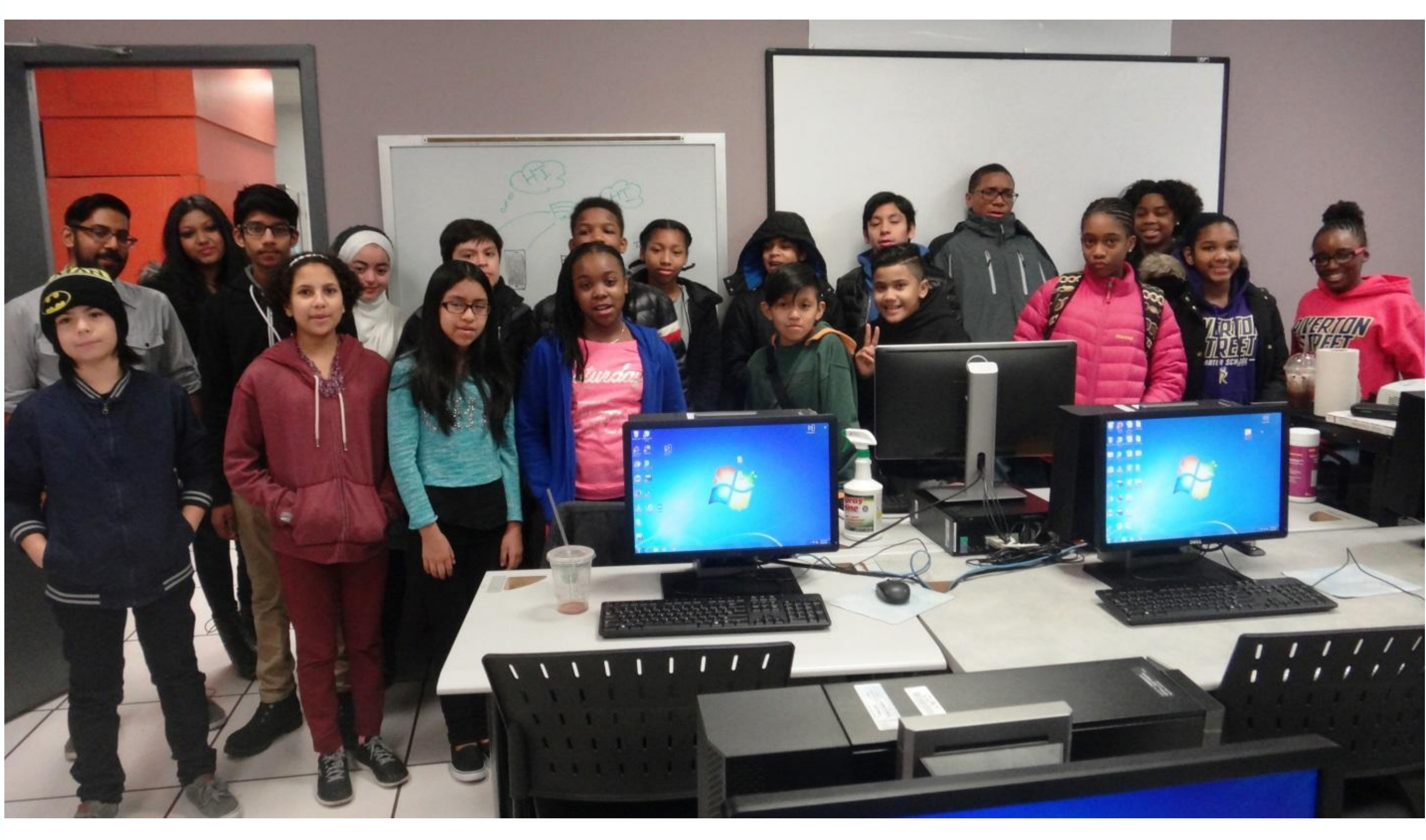

Conclusion

As part of the curriculum enhancement activity (CEA), Climate Change Education (CCE) offered to the younger grades also enabling them to become familiar with basic science concepts and their ultimate constraints related to present days extreme climate scenarios.

Students learn at an early age (10 or above) to retrieve NASA online climate data and run tasks to delineate factors connected with rising air temperature and predict future trends as well.

To make it real, students are given NASA data on New York City's Central Park and it certainly motivates students to engage in CCE exercises and enables them to comprehend the functionality of basic mathematics and meteorology-related concepts in addition to anthropogenic causes of global climate change.

Integration of multidisciplinary STEM subjects coupled with ELO research activities at an early motivating K9-16 and their relevance to geosciences. From recruitment and retention point of view, it should be viewed as being of utmost academic importance. 